\title{
Mean girls: Provocative clothing leads to intra-sexual competition between females
}

\author{
Eleanor Keys and Manpal Singh Bhogal (ㅁ66430@ coventry.ac.uk)
}

Corresponding Author: Manpal Singh Bhogal, Coventry University, School of Psychological, Social and Behavioural Sciences, Psychology Department, Richard Crossman Building, Priory Street, Coventry, CV1 5FB, UK. Tel: 02477 654623. Email: ab6430@coventry.ac.uk

\begin{abstract}
This study aimed to investigate indirect aggression between females from an evolutionary perspective, considering indirect aggression as a mechanism of intra-sexual competition. Previous research suggests that females who are dressed provocatively, or appear 'sexually available', are more likely to be victims of indirect aggression from other females. Investigating this notion via an empirical measure and a word-selection task, this study involved a female confederate posing as a participant, who was dressed provocatively in one condition and conservatively in the other. Sixty-five females completed an intra-sexual competition scale and a word selection task in which they were able to select complimentary or derogatory phrases to describe the confederate. Making derogative comments is a common form of indirect aggression; therefore, those who selected derogatory phrases could be considered to be exhibiting indirect aggression. Consistent with our hypotheses, participants in the provocative condition obtained significantly higher intra-sexual competition scores and selected more derogatory words than those in the conservative condition, indicating that females dressed provocatively are indirectly aggressed against to a greater extent than those that are not. This paper adds further support to the notion that indirect aggression is used by females as a method of intra-sexual competition, particularly towards provocatively dressed females.
\end{abstract}

Keywords: Intra-female competition, sexual selection, provocative clothing, word selection 
Evolutionary psychology applies natural selection (Darwin, 1859) to explain psychological adaptations and behaviours (Confer et al., 2010; Tooby \& Cosmides, 2005). Natural selection refers to the process whereby individuals possessing traits that are advantageous to their survival, are more likely to survive, therefore passing these traits onto subsequent generations (Workman \& Reader, 2014). However, survival is not only dependent on the possession of genetic attributes that increase chances of survival, but also on attributes that increase reproduction success (Buss \& Schmitt, 1993). It is these traits, that exclusively increase reproductive opportunities that led to the development of Darwin's theory of Sexual Selection (Darwin, 1871).

Sexual selection is described as 'competition for mates' (Shuker, 2010) and the 'survival of the sexiest' (Nettle, 2009, p. 65). The basis of both definitions is that sexual selection describes traits that are advantageous when competing with others for mates and increase an individual's mating successes (Hoelzer, 1989). Sexual selection operates through two processes: inter-sexual competition and intra-sexual competition. Inter-sexual competition refers to members of one sex selecting mates from the other sex on account of the possession of attractive qualities (Buss, 1988). Intra-sexual competition occurs when members of the same-sex compete against each other in order to gain access to opposite-sex mates of high quality (Miller, 2013), which is the theoretical foundation of this paper.

\section{Intra-Sexual Competition and Aggression}

Intra-sexual competition can be manifested via derogation of rivals, achieved by reducing the value of a competitor in the mating market, and self-promotion, increasing one's own value in the mating market (Schmitt \& Buss, 1996). Darwin indicated that sexual selection is dependent 'not on a struggle for existence, but on a struggle between the males for the possession of the females' (Darwin, 1859, p.88). In this context, females are the limited 
resource, and, as Darwin theorised, intra-sexual competition typically occurred exclusively between males in competition for female mates (Hunt et al. 2009).

Trivers (1972) offered an explanation for this dynamic through parental investment theory, noting that females invest far more into offspring than males, starting with costlier gamete production, leading all the way to rearing and nurturing offspring to maturity (Campbell, 2013). This high level of investment means that a female's potential reproductive success is far more limited than a male's, which is only limited by the number of females with whom he mates (Bateman, 1948). As a result, males are more concerned with the quantity of mates they obtain, whereas females are more concerned with the quality of their mates (Geary et al., 2004), making females the choosier sex in mate choice. As a result, males compete with each other in order to obtain access to females (Archer, 2009).

Several studies have found that females exhibit indirect aggression significantly more than males (Björkqvist, 1994; Björkqvist et al., 1994; Hess \& Hagen, 2006; Salmivalli \& Kaukiainen, 2004; Vaillancourt, 2013), whereas males typically engage in acts of direct aggressive, physical confrontation with other males in order to compete for access to females (Buunk \& Fisher, 2009). However, females engage in indirect aggression as a mate attraction strategy, and as a derogation tactic aimed to reduce a rival's mate value in the mating market (Campbell, 2013; Fisher \& Cox, 2009; Vaillancourt 2005, 2011). In turn, engaging in indirect aggression increases a female's self-esteem, self-image, mating successes and mate value (Galen \& Underwood, 1997). Mate value describes the total notional value of traits possessed by an individual that contribute to their reproductive success (i.e. physical attractiveness, height etc., see Waynforth, 2001). 
Indirect aggression relates to aggressive acts that inflict psychological or social, rather than physical harm (Lagerspetz et al., 1988). As with physical aggression, there is an attacker (or attackers) inflicting harm on an individual; however, the tactics used by the attacker tend to be allow them to remain unidentifiable and therefore able to avoid counterattack from the victim (Björkqvist et al., 1992). Indirect aggression can be manifested in a number of ways, such as the exclusion of a peer from the group, gossiping, or spreading rumours, convincing others to dislike someone, making derogative comments, or simply using derisive body and facial gestures to cause others to feel self-consciousness (Buss, 1961; Coyne et al., 2006; Dunbar, 2004; Vaillancourt, 2013).

The age at which indirect aggression is most prevalent in females suggests that there is a mating motive behind the act (Vaillancourt, 2013). Indirect aggression is most commonly used by females in adolescence and young adulthood, the peak years of reproductive activity, when females are most fertile (Archer, 2004; Hess \& Hagen, 2006; Massar et al., 2012; Underwood et al., 2009). In addition, indirect aggression exhibited by females tends to be directed at other females rather than males, particularly towards attractive, than unattractive females (Arnocky et al., 2012; Paquette \& Underwood, 1999; Vaillancourt, 2013).

\section{Intra-sexual competition, physical attractiveness and clothing}

Attractive features in males and females have been guided by mate choice, or intersexual selection (Bateson, 1983). The preferences of one sex dictate which traits members of the opposite sex find attractive, projected by both males and females when seeking a mate (Buss, 1988; Campbell, 2013; Halliday, 1983). Physical attractiveness is one of the strongest predictors of a female's mate value, and attractiveness is a highly sought trait (Buss, 1989; Singh, 1993; Symons, 1995; Taylor \& Glenn, 1976; Udry \& Eckland, 1984). Physically attractive females are consistently preferred by males as mates (Buss \& Schmitt, 1993). 
Therefore, females compete with one another in domains of physical attractiveness, promoting and enhancing features that males find attractive (Cashdan, 1998; Schmitt \& Buss, 1996). In support, attractive females are considered a threat to other females (Lee et al., 2015). This may act as an explanation for female use of makeup (Vaillancourt, 2013; Etcoff, 1999), as it is used to emphasise features deemed attractive by males.

Smith et al. (2006) found that females who wore makeup were rated as more attractive, feminine and healthy than those without makeup. Makeup, therefore, may act as a form of selfpromotion aimed at increasing levels of one's mate value (Fisher \& Cox, 2009). Whether this is achieved through methods of self-promotion, females who are considered more physically attractive have been found to be at greater risk of being victims of indirect aggression from other females (Vaillancourt, Miller \& Sharma, 2010; Vaillancourt \& Sharma, 2011). In support, sexual availability and promiscuity have been found to significantly increase victimisation via indirect aggression in females (Campbell, 1995; Leenaars, Dane \& Marini, 2008; Gallup et al., 2009;), but not males (Gallup, O’Brien \& Wilson, 2011). Baumeister and Twenge (2002) suggest that this is because sex is considered a limited resource that is used by females to negotiate with males; therefore, females who make sex too readily available cause other females to feel threatened. These points support the fact that females possessing features that are attractive to males, are more likely to be victims of indirect aggression from other females (Leenaars, Dane \& Marini, 2008).

One of the methods by which females are considered to communicate sexual availability is through clothing. Grammer et al. (2004) found that a female's clothing may reflect sexual availability, and promiscuity, with tighter, sheerer outfits that display more skin correlating with sexual availability. Colour choices also communicate sexual promiscuity, with a large body of research indicating that the colour red is worn by females to convey sexual 
availability and is considered attractive by males (Beall \& Tracy, 2013; Elliot et al., 2013; Schwarz \& Singer, 2013). Clothes therefore act as a form of self-promotion; dressing in a manner that accentuates one's figure may draw attention to physical traits that males consider attractive and are indicative of a female's mate value (Buss, 1988). As a result, provocative clothing has been found to make other females feel strongly threatened, and is often met with indirect aggression as a form of punishment (Vaillancourt \& Sharma, 2011).

Vaillancourt and Sharma (2011) explored intra-sexual competition, and indirect aggression in females, in a sample of 86 female participants between the ages of 19 and 23 . The study involved two conditions where either a provocatively or a conservatively dressed female entered a room. Participants' reactions were video recorded, analysed and coded as either 'bitchy' or 'not bitchy'. The results indicated that most females in the provocatively condition indirectly aggressed against her through their body language, such as 'rolling their eyes', and verbal means, such as making comments about her appearance and sexual promiscuity. This research suggests females use forms of indirect aggression in order to derogate competitors as a method of intra-sexual competition. The present study was partially based on the above research, aiming to replicate the strong effects found in their research, with the addition of an empirical intra-sexual competition scale.

\section{The present study}

The aim of our study was to assess whether the presence of a provocatively dressed female confederate would result in higher levels of intra-sexual competition (through a selfreport scale) and derogation through word selection (using a word selection task). Therefore, based on the literature discussed, we proposed three hypotheses; 
Hypothesis 1: Females exposed to a provocatively dressed confederate would report higher intra-sexual competition scores than females exposed to a conservatively dressed confederate

Hypothesis 2: More derogatory comments would be selected by female participants who are exposed to the provocatively dressed confederate than by those describing the conservatively dressed confederate.

Hypothesis 3: More complimentary words would be chosen by participants who are exposed to the conservatively dressed confederate than the provocatively dressed confederate.

\section{Method}

Design

This study adopted a between-groups design. The independent variable was the clothing worn by the confederate: provocative or conservative. These conditions were counterbalanced. There were three dependent variables; the first was the level of intra-sexual competition, measured via an intra-sexual competition scale. The second was indirect aggression, measured as the number of derogative phrases selected by the participant to describe the confederate via a word selection task. The third DV was the number of complimentary words chosen by the participant to describe the confederate.

\section{Participants}

Sixty-five female students took part, with 30 in the conservative condition and 35 in the provocative condition (mean age $=20, S D=1.85$ ). The sample was heterosexual. Participants were recruited through a volunteer sampling method using the host universities student research participation scheme. Female participants between the ages of 18 and 28 were 
recruited to reflect peak reproductive age (see Dunson, Colombo \& Baird, 2002; Hassan \& Killick, 2003).

In addition to our sample, we required the participation of a confederate who was available to assist when collecting data, consented to having her image included in a paper, and who had low hip to weight ratio. Furthermore, participants needed to believe that she was a participant rather than a confederate. It was vital that participants were not familiar with the confederate, to ensure that their judgements about her were based solely on her clothing and not her personality or other confounding variables. Subsequently, in order to avoid familiarity effects between the participant and confederate, a further prerequisite for the confederate was that they must not be a psychology student. The confederate was selected using opportunity sampling at the host university via the research participation scheme. She was a 21-year-old female student, studying at the host university.

\section{Materials}

The intra-sexual competition scale used was created by Buunk and Fisher (2009). Cronbach alpha analysis suggested this scale was very reliable in our sample $(\alpha=.92)$. The scale includes 12 statements where participants must rate the statements from 1 (not at all applicable) to 7 (completely applicable). For example, items on the scale include 'I can't stand it when I meet another woman who is more attractive than I am' and 'I enjoy it when men pay more attention to me than to other women'.

\section{Word selection task}

We also created a word selection task to measure indirect aggression, whereby participants choose derogatory/complimentary words/phrases to describe the confederate. Prior to administering the task, we compiled a list of derogatory and complimentary words/phrases. The initial list comprised of 40 phrases, 20 complimentary and 20 derogatory. We then reduced 
the phrases to ten derogatory and ten complimentary phrases via asking a sample of 15 female undergraduate students from the host university (mean age $=21, S D=0.79$ ) to identify which phrases (from the 40) they considered to be most complimentary and derogatory. All 15 participants categorised the phrases as either derogatory (10) or complimentary (10), with the final list being used in the study.

\section{Procedure $^{1}$}

The consent of the confederate was gained prior to collecting data. The two outfits worn by the confederate were heavily based on the outfit choices in Vaillancourt and Sharma's research as well as a large body of evidence indicating that females with clear skin, youthful, feminine facial features and a low waist-to-hip ratio are considered attractive (Dixson et al., 2011; Jasienska et al., 2006; Marlowe et al., 2005). Therefore, in the provocative condition, clothing and makeup that accentuated these features were selected. In the conservative condition, we chose minimal makeup and clothing that covered the body. Colours worn by the confederate were chosen based on findings that indicate the colour red acts as a sexual signal, and sexual availability (Beall \& Tracy, 2013; Elliot et al., 2013; Schwarz \& Singer, 2013) and the colour green has the lowest association with sexual availability (Elliot et al., 2012). Therefore, the colour green was incorporated into the conservative outfit and the colour red into the provocative outfit (see supplementary materials).

Participants selected the timeslot through the research participation system. There was a 10-minute gap between timeslots to allow the confederate to exit the room, ensuring anonymity between participants. To further ensure that participants were unaware of the

\footnotetext{
${ }^{1}$ This study was approved by the host universities research ethics committee. Informed consent was obtained from all individual participants included in the study. Additional informed consent was obtained from all individual participants (confederate) for whom identifying information is included in this article.
} 
confederate's role, signs were placed outside the lab instructing participants who were early, to wait elsewhere in the building.

Once the participant arrived at the lab, she was presented with relevant ethical forms. As the participant was reading and completing relevant forms, the researcher sent a text message to the confederate, who was waiting in a nearby corridor, to enter the room. This ensured that the confederate appeared to be a genuine participant. At each stage of the study, the confederate was treated as if she were a participant. Both the participant and the confederate were given a demographic questionnaire, intra-sexual competition scale and word selection task, which were completed whilst the confederate was in the room.

The word task was a randomly ordered list of ten complimentary and ten derogatory words or phrases that may be used to describe the confederate. Participants were asked to circle the phrases they felt described the confederate they were advised to circle as many words/phrases as they wished (the confederate was also given this task in order to increase realism). Once complete, the confederate, and female participant were asked to place these questionnaires into envelopes and then into a sealed box to ensure anonymity. Throughout the study, the confederate communicated with the participant minimally, as it was important that judgements should not be made based on verbal communication.

\section{Results}

We conducted a one-way ANOVA to measure differences in intra-sexual competition scores, the number of derogative words and complimentary words between conditions where the confederate was dressed provocatively and conservatively. We found a significant difference in intra-sexual competition scores, with females in the provocative condition having higher intra-sexual competition scores than those in the conservative condition, $F(1,64)=$ 
7.37, $p=.01, \eta^{2}=.10$. We found a significant difference in the number of derogative words chosen, with females choosing more derogatory words to describe the confederate dressed provocatively than when she was dressed conservatively, $F(1,64)=4.65, p=.04, \eta^{2}=.01$. Finally, we found a significant difference in the number of complimentary words chosen, with females choosing more complimentary words when describing the conservatively dressed female, $F(1,64)=11.51, p=.00 \eta^{2}=.15$. The results support all three of our experimental hypotheses as females exposed to provocative clothing had higher intra-sexual competition scores, and they chose more negative words in the word selection task. Females in the conservative condition chose more complimentary words to describe the confederate than females in the provocatively dressed condition. Descriptive statistics are provided in table 1.

\section{[insert table 1]}

\section{Discussion}

We hypothesised that females in the provocative condition would gain higher scores on the intra-sexual competition scale, would select more derogatory words and less complimentary words to describe the confederate than those in the conservative condition, which were all supported. We found that the presence of a provocatively dressed female led other females to display higher levels of intra-sexual competition and indirect aggression, inferred from derogatory comments selected to describe another female.

Our findings are consistent with Vaillancourt and Sharma (2011) and previous research into indirect aggression finding females possessing traits valued by males are more likely to be indirectly aggressed against (Gallup et al., 2009; Leenaars, Dane \& Marini, 2008; Vaillancourt, 2013). The clothes worn by the confederate in the provocative condition aimed to emphasise 
traits that equate to a high mate value, such as exaggerated makeup (Fisher \& Cox, 2009; Smith et al., 2006; Vaillancourt, 2013) and clothing that conveyed sexuality through the colour red (Beall \& Tracy, 2013; Schwarz \& Singer, 2013) and accentuated aspects of her figure, typically deemed attractive to males (Dixson et al., 2011, Jasienska et al., 2006; Marlowe et al., 2005). Our findings are consistent with the predictions of sexual selection theory, particularly intrasexual competition between females, providing support that there is an evolutionary basis to explain indirect aggression between females.

Much of the previous research into indirect aggression has used measures that remove the act of aggression, by using hypothetical situations or vignettes (Archer, 2004; Coyne, Archer \& Eslea, 2006; Hess \& Hagan, 2006). Observational studies, such as Vaillancourt and Sharma's (2011) study, from which this design of the current research was derived, allows participants to actually indirectly aggress against others. The use of a laboratory experiment enabled a high level of control over extraneous variables. We ensured that the participants did not know the confederate, they were unaware of her role, and the aims of the study were well concealed. Therefore, in this study, the participants' judgements of the confederate and their responses to each task seem to be based solely on the appearance of the confederate. Furthermore, although research has been conducted to similar effect, and we have replicated the findings of previous research, we included alternative measures which have not been adopted in previous research. For example, we created an alternative measure to infer indirect aggression (word selection task to measure both derogatory and complimentary phrases), and we included an empirical measure of intra-sexual competition instead of inferring intra-sexual competition from indirect aggression alone, making a novel contribution to the literature.

There are certain explanations for our findings which should be noted. The derogatory comments made by participants against the provocatively dressed confederate may be 
considered a form of social control resulting from norm violation (Brauer \& Chekroun, 2005). Provocative clothing may be considered as defying conventional dress and social norms; therefore, derogatory comments may be a form of control used to punish those who violate social rules (Vaillancourt \& Sharma, 2011). As the females in the study were university students, provocative clothing may not be perceived as an extreme norm violation, considering the lifestyle attributed to students (McAnulty, 2012). However, clothing choices have been found to have an impact on how an individual is perceived (Gille-Knauf \& Mittag, 2008), with provocative clothing often leading one to be perceived negatively (Edmonds et al., 1992; Glick et al., 2005; Graff et al., 2012). As a result, the phrases chosen to describe the provocatively dressed female may be the result of how she was perceived rather than an act of aggression. In addition, perhaps a pre-test could have been conducted whereby an independent sample could have evaluated the confederate in domains such as physical attractiveness.

Despite this paper's strengths in providing preliminary support for our hypotheses, there are also some notable limitations. First, although making derogative comments about another individual is considered a common form of indirect aggression and has been well documented in previous research (Benenson, 2009; Cox \& Fisher, 2008; Low et al., 2010), our measure of indirect aggression was not a psychometric test, and may be considered to lack reliability and validity, particularly as the final word set was chosen by a limited sample. Second, the study sample was relatively small. A larger sample would allow the findings of this study to be supported and improve generalisability. Due to the small sample size, our findings should be taken with caution. Third, the role of self-rated attractiveness in indirect aggression was not assessed. Previous research suggests that self-rated attractiveness influences how we behave towards others (see Bhogal, Galbraith \& Manktelow, 2016c; Stirrat et al., 2011). Perhaps future research could replicate this study with the inclusion of self-rated 
attractiveness. Fourth, the negative words chosen to be used in the word selection task appeared to be very negative compared to the positive words. As a result, female participants who had not met the confederate may have been unlikely to circle completely derogative words. This is evidenced by the significant, yet small difference between positive and negative words chosen by our participants. Fifth, we did not take females' menstrual cycle into account. Research suggests that females exhibit higher intra-sexual competition when ovulating, and when taking hormonal birth control (see Cobey, Roberts \& Buunk, 2013). Sixth, female participants may have felt more comfortable, and less threated by the confederate dressed conservatively as opposed to when dressed provocatively. Last, we did not take the Dark Triad personality traits into account, as recent evidence suggests that there is a relationship between psychopathy and engaging in mate poaching strategies (see Erik \& Bhogal, 2016). Furthermore, there is research to suggest that females experience higher body dissatisfaction when viewing images of other females who signal sexual competitiveness through dress, particularly when a potential mate is available (see study 1 of Ferguson, Munoz, Contreas \& Velasquez, 2011).

Indirect aggression can be observed in everyday life. Several studies have found that females, more than males exhibit indirect aggression in school as a form of bullying, which has long-lasting, damaging effects on self-esteem and dating behaviours (Gallup et al., 2011; Pellegrini \& Long, 2003; White et al., 2010). Therefore, the more that is understood about indirect aggression and its use, the more these behaviours can be prevented. Furthermore, should indirect aggression be a component of intra-sexual competition, these behaviours would be present in females beyond school age, despite bullying often only being focused on adolescents and young adults (Baughman et al., 2011). Females also exhibit indirect aggression in the workplace, more than males (Crothers et al., 2009), which highlights the importance of awareness and prevention of victimisation in a wide variety of contexts. Furthermore, future 
research should focus on cyber-bullying as cyberbullying entails elements of indirect aggression (Smith et al., 2013). Jackson et al. (2013) found that females engage in cyberbullying at higher rates than males, often adopting indirect aggressive tactics such as 'slut shaming', whereby females are shamed for their perceived sexual availability is extremely prevalent in cyberspace, as well as in schools (Webb, 2015). Our paper suggests that females who are perceived to be dressed provocatively are indirectly aggressed against. Therefore, studying online behaviours in the context of evolutionary theory, in this instance indirect aggression, may help to deal with prominent, modern-day issues (McAndrew, 2014).

\section{Compliance with Ethical Standards}

There are no conflicts of interest. This research involved collecting data from human participants. Informed consent was taken from all participants who took part in this study. All procedures performed in studies involving human participants were in accordance with the ethical standards of the institutional and/or national research committee and with the 1964 Helsinki declaration and its later amendments or comparable ethical standards. 


\section{References}

Archer, J. (2004). Sex Differences in Aggression in Real-World Settings: A Meta-Analytic Review'. Review of General Psychology, 8(4), 291-322. doi: 10.1037/1089-2680.8.4.291

Archer, J. (2009). Does Sexual Selection Explain Human Sex Differences in Aggression? Behavioral and Brain Sciences, 32, 249-266. doi: 10.1017/s0140525x09990951

Archer, J. (2010). What Is Indirect Aggression in Adults. In W. Osterman (Ed.), Indirect and Direct Aggression (pp. 3-16). Oxford: Peter Lang. doi: 10.1037/e554382012-149

Arnocky, S., Sunderani, S., Miller, J. L., \& Vaillancourt, T. (2012). Jealousy Mediates the Relationship between Attractiveness Comparison and Females' Indirect Aggression. Personal Relationships, 19(2), 290-303. doi: 10.1111/j.1475-6811.2011.01362.x

Bateman, A. J. (1948). Intra-Sexual Selection in Drosophila. Heredity, 2(3), 349-368. doi: 10.1038/hdy.1948.21

Bateson, P. P. G. (1983). Mate Choice. Cambridge: Cambridge University Press.

Baughman, H. M., Dearing, S., Giammarco, E., \& Vernon, P. A. (2011). Relationships between Bullying Behaviours and the Dark Triad. Personality and Individual Differences, 52, 571-575. doi: 10.1016/j.paid.2011.11.020

Baumeister, R. F., \& Twenge, J. M. (2002). Cultural Suppression of Female Sexuality. Review of General Psychology, 6, 166-203. doi: 10.1037/1089-2680.6.2.166

Beall, A. T., \& Tracy, J. L. (2013). Women Are More Likely to Wear Red or Pink at Peak Fertility. Psychological Science, 24(9), 1837-1841. doi: 10.1177/0956797613476045 
Benenson, J. F. (2009). Dominating versus Eliminating the Competition: Sex Differences in Human Intra-Sexual Competition. Behavioral and Brain Sciences, 32, 268-269. doi: $10.1017 / \mathrm{s} 0140525 \mathrm{x} 0999046 \mathrm{x}$

Bhogal, M. S., Galbraith, N., \& Manktelow, K. (2016c). Physical attractiveness and altruism in two modified dictator games. Basic and Applied Social Psychology, 38(4), 212-222. doi.org/10.1080/01973533.2016.1199382

Björkqvist, K. (1994). Sex Differences in Physical, Verbal and Indirect Aggression: A Review of Recent Research. Sex Roles, 30, 177-188. doi: 10.1007/bf01420988

Björkqvist, K., Österman, K., \& Kaukiainen, A. (1992). The Development of Direct and Indirect Aggressive Strategies in Males and Females'. In K. Björkqvist \& P. Niemela (Ed.), Of Mice and Women: Aspects of Female Aggression (pp. 51-64). California: Academic Press Inc. doi: 10.1016/b978-0-12-102590-8.50010-6

Björkqvist, K., Osterman, K., \& Lagerspetz, K. M. (1994). Sex Differences in Covert Aggression among Adults. Aggressive Behavior, 20(1), 27-33. doi: 10.1002/10982337(1994)20:1<27::aid-ab2480200105>3.0.co;2-q

Brauer, M., \& Chekroun, P. (2005). The Relationship between Perceived Violation of Social Norms and Social Control: Situational Factors Influencing the Reaction to Deviance. Journal of Applied Social Psychology, 35(7), 1519-1539. doi: 10.1111/j.1559-1816.2005.tb02182.x

Burley, N. (1977). Parental Investment, Mate Choice, and Mate Quality. Proceedings of the National Academy of Sciences, 74(8), 3476-3479. doi: 10.1073/pnas.74.8.3476

Buss, A. H. (1961). The Psychology of Aggression. New York: Wiley. doi: 10.1037/11160000 
Buss, D. M. (1988). The Evolution of Human Intra-Sexual Competition: Tactics of Mate Attraction. Journal of Personality and Social Psychology, 54(4), 616. doi: 10.1037/00223514.54.4.616

Buss, D. M. (1989). Sex differences in human mate preferences: Evolutionary hypotheses tested in 37 cultures. Behavioural and brain sciences, 12(1), 1-14. doi: $10.1017 / \mathrm{s} 0140525 \times 00023992$

Buss, D. M. (1995). Psychological Sex Differences: Origins through Sexual Selection. American Psychologist, 50(3), 164-168. doi: 10.1037/0003-066x.50.3.164

Buss, D. M., \& Schmitt, D. P. (1993). Sexual Strategies Theory: An Evolutionary Perspective on Human Mating. Psychological Review, 100(2), 204-232. doi: 10.1037/0033-295x.100.2.204 Buunk, A. P., \& Fisher, M. (2009). Individual Differences in Intra-Sexual Competition. Journal of Evolutionary Psychology, 7(1), 37-48. doi: 10.1556/jep.7.2009.1.5

Campbell, A. (1995). A Few Good Men: Evolutionary Psychology and Female Adolescent Aggression. Ethology and Sociobiology, 16(2), 99-123. doi: 10.1016/0162-3095(94)00072-f

Campbell, A. (1999). Staying Alive: Evolution, Culture, and Women's Intra-Sexual Aggression. Behavioral and Brain Sciences, 22(2), 203-214. doi: $10.1017 / \mathrm{s} 0140525 \times 99001818$

Campbell, A. (2006). Sex Differences in Direct Aggression: What Are the Psychological Mediators? Aggression and Violent Behavior, 11(3), 237-264. doi: 10.1016/j.avb.2005.09.002 Campbell, A. (2013). A Mind of Her Own: The Evolutionary Psychology of Women. Oxford: Oxford University Press. doi: 10.1093/acprof:oso/9780199609543.001.0001 
Cashdan, E. (1998). Are Men More Competitive than Women? British Journal of Social Psychology, 37(2), 213-229. doi: 10.1111/j.2044-8309.1998.tb01166.x

Cobey, K. D., Roberts, S. C., \& Buunk, A. P. (2013). Hormonal contraceptive congruency: Implications for relationship jealousy. Personality and Individual Differences, 55, 569- 573.

Confer, J. C., Easton, J. A., Fleischman, D. S., Goetz, C. D., Lewis, D. M., Perilloux, C., \& Buss, D. M. (2010). Evolutionary Psychology: Controversies, Questions, Prospects, and Limitations. American Psychologist, 65(2), 110-126. doi: 10.1037/a0018413

Cox, A., \& Fisher, M. (2008). A Framework for Exploring Intra-Sexual Competition. Journal of Social, Evolutionary, and Cultural Psychology, 2(4), 144-155. doi: 10.1037/h0099348

Coyne, S. M., Archer, J., \& Eslea, M. (2006). "We're Not Friends Anymore! Unless...”: The Frequency and Harmfulness of Indirect, Relational, and Social Aggression. Aggressive Behavior, 32(4), 294-307. doi: 10.1002/ab.20126

Crothers, L. M., Lipinski, J., \& Minutolo, M. C. (2009). Cliques, Rumours, and Gossip by the Water Cooler: Female Bullying in the Workplace. The Psychologist-Manager Journal, 12(2), 97-110. doi: 10.1080/10887150902886423

Darwin, C. (1859). On the Origin of Species. London: John Murray. doi: $10.9783 / 9780812200515$

Darwin, C. R. (1871). The Descent of Man, and Selection in Relation to Sex. London: John Murray. doi: 10.5962/bhl.title.24784

Dixson, B. J., Grimshaw, G. M., Linklater, W. L., \& Dixson, A. F. (2011). Eye-Tracking of Men's Preferences for Waist-to-Hip Ratio and Breast Size of Women. Archives of Sexual Behavior, 40(1), 43-50. doi: 10.1007/s10508-010-9601-8 
Dunbar, R. I. (2004). Gossip in Evolutionary Perspective. Review of General Psychology, 8(2), 100-110. doi: 10.1037/1089-2680.8.2.100

Dunson, D. B., Colombo, B., \& Baird, D. D. (2002). Changes with Age in the Level and Duration of Fertility in the Menstrual Cycle. Human Reproduction, 17(5), 1399-1403. doi: 10.1093/humrep/17.5.1399

Edmonds, E. M., Cahoon, D. D., \& Hudson, E. (1992). Male-Female Estimates of Feminine Assertiveness Related to Females' Clothing Styles. Bulletin of the Psychological Society, 30(2), 143-144. doi: 10.3758/bf03330422

Elliot, A. J., Greitemeyer, T., \& Pazda, A. D. (2013). Women's Use of Red Clothing as a Sexual Signal in Intersexual Interaction. Journal of Experimental Social Psychology, 49(3), 599-602. doi: 10.1016/j.jesp.2012.10.001

Elliot, A. J., Pazda, A. D., \& Greitemeyer, T. (2012). Sexy Red: Perceived Sexual Receptivity Mediates the Red-Attraction Relation in Men Viewing Woman. Journal of Experimental Social Psychology, 48(3), 787-790. doi: 10.1016/j.jesp.2011.12.009

Erik, E., \& Bhogal, M. S. (2016). Do the Dark Triad and self-perceived mate value predict intention to mate poach? Letters on Evolutionary Behavioral Science, 7(2), 1-4. doi: $10.5178 /$ lebs. 2016.50

Etcoff, N. (1999). Survival of the prettiest. London: Little, Brown and Company. doi:

Ferguson, C. J., Munoz, M. E., Contreas, S., \& Velasquez, K. (2011). Mirror, Mirror on the wall: Peer competition, television influences, and body image dissatisfaction. Journal of Social \& Clinical Psychology, 30(5), 458-483. 
Fisher, M. L. (2004). Female Intra-Sexual Competition Decreases Female Facial Attractiveness. Proceedings of the Royal Society of London B: Biological Sciences, 271, 283285. doi: $10.1098 / \mathrm{rsbl} .2004 .0160$

Fisher, M., \& Cox, A. (2009). The Influence of Female Attractiveness on Competitor Derogation. Journal of Evolutionary Psychology, 7(2), 141-155. doi: 10.1556/jep.7.2009.2.3

Galen, B. R., \& Underwood, M. K. (1997). A Developmental Investigation of Social Aggression among Children. Developmental Psychology, 33(4), 589-600. doi: 10.1037/00121649.33.4.589

Gallup, A. C., O’Brien, D. T., \& Wilson, D. S. (2011). Intra-Sexual Peer Aggression and Dating Behavior during Adolescence: An Evolutionary Perspective. Aggressive Behavior, 37(3), 258267. doi: 10.1002/ab.20384

Gallup, A. C., O’Brien, D. T., White, D. D., \& Wilson, D. S. (2009). Peer Victimization in Adolescence has Different Effects on the Sexual Behavior of Male and Female College Students. Personality and Individual Differences, 46(5), 611-615. doi: 10.1016/j.paid.2008.12.018

Geary, D. C., Vigil, J., \& Byrd-Craven, J. (2004). Evolution of Human Mate Choice. Journal of Sex Research, 41(1), 27-42. doi: 10.1080/00224490409552211

Gille-Knauf, T. R., \& Mittag, R. M. (2008). Smart and Sexy? Major and Clothing's Influence on Perceptions of Intelligence. UW-L Journal of Undergraduate Research, 6, 1-9. doi: $10.1037 / \mathrm{e} 617962012-577$ 
Glick, P., Larsen, S., Johnson, C., \& Branstiter, H. (2005). Evaluations of Sexy Women in Low-and High-Status Jobs. Psychology of Women Quarterly, 29(4), 389-395. doi: 10.1111/j.1471-6402.2005.00238.x

Graff, K., Murnen, S. K., \& Smolak, L. (2012). Too Sexualized to Be Taken Seriously? Perceptions of a Girl in Childlike vs. Sexualizing Clothing. Sex Roles, 66, 764-775. doi: $10.1007 / \mathrm{s} 11199-012-0145-3$

Grammer, K., Renninger, L., \& Fischer, B. (2004). Disco Clothing, Female Sexual Motivation, and Relationship Status: Is She Dressed to Impress? Journal of Sex Research, 41(1), 66-74. doi: $10.1080 / 00224490409552214$

Halliday, T. R. (1983). Mate Choice. Cambridge: Cambridge University Press. doi:

Hassan, M. A., \& Killick, S. R. (2003). Effect of Male Age on Fertility: Evidence for the Decline in Male Fertility with Increasing Age. Fertility and Sterility, 79, 1520-1527. doi: 10.1016/s0015-0282(03)00366-2

Hess, N. H., \& Hagen, E. H. (2006). Sex Differences in Indirect Aggression: Psychological Evidence from Young Adults. Evolution and Human Behavior, 27(3), 231-245. doi: 10.1016/j.evolhumbehav.2005.11.001

Hoelzer, G. A. (1989). The Good Parent Process of Sexual Selection. Animal Behaviour, 38(6), 1067-1078. doi: 10.1016/s0003-3472(89)80146-0

Hunt, J., Breuker, C. J., Sadowski, J. A., \& Moore, A. J. (2009). Male-Male Competition, Female Mate Choice and Their Interaction: Determining Total Sexual Selection. Journal of Evolutionary Biology, 22(1), 13-26. doi: 10.1111/j.1420-9101.2008.01633.x 
Jackson, M., Cassidy, W., \& Brown, K. N. (2013). "You Were Born Ugly and You'll Die Ugly Too'. Cyber-Bullying as Relational Aggression. Education, 15(2). Available online at http://ineducation.ca/ineducation/article/view/57.

Jasienska, G., Lipson, S. F., Ellison, P. T., Thune, I., \& Ziomkiewicz, A. (2006). Symmetrical Women Have Higher Potential Fertility. Evolution and Human Behavior, 27(5), 390-400. doi: 10.1016/j.evolhumbehav.2006.01.001

Lagerspetz, K. M., Björkqvist, K., \& Peltonen, T. (1988). Is Indirect Aggression Typical of Females? Gender Differences in Aggressiveness in 11-to 12-Year-Old Children. Aggressive Behavior, 14(6), 403-414. doi: 10.1002/1098-2337(1988)14:6<403::aidab2480140602>3.0.co;2-d

Lee, Sunyong, Pitesa, M., Pillutla, M., \& Thau, S. (2015). When beauty helps and when it hurts: An organizational context model of attractiveness discrimination in selection decisions. Organizational Behavior and Human Decision Processes, 128, 15-28. doi: 10.1016/j.obhdp.2015.02.003

Leenaars, L. S., Dane, A. V., \& Marini, Z. A. (2008). Evolutionary Perspective on Indirect Victimization in Adolescence: The Role of Attractiveness, Dating and Sexual Behavior. Aggressive Behavior, 34(4), 404-415. doi: 10.1002/ab.20252

Low, S., Frey, K. S., \& Brockman, C. J. (2010). Gossip on the Playground: Changes Associated with Universal Intervention, Retaliation Beliefs, and Supportive Friends. School Psychology Review, 39(4), 536. 
Marlowe, F., Apicella, C., \& Reed, D. (2005). Men's Preferences for Women's Profile Waistto-Hip Ratio in Two Societies. Evolution and Human Behavior, 26(6), 458-468. doi: 10.1016/j.evolhumbehav.2005.07.005

Massar, K., Buunk, A. P., \& Rempt, S. (2012). Age Differences in Women's Tendency to Gossip are Mediated by Their Mate Value. Personality and Individual Differences, 52(1), 106109. doi: $10.1016 /$ j.paid.2011.09.013

McAndrew, F. T. (2014). The "Sword of a Woman": Gossip and Female Aggression. Aggression and Violent Behavior, 19(3), 196-199. doi: 10.1016/j.avb.2014.04.006

McAnulty, R. (2012). Sex in College - The Things They Don't Write Home About. California: ABC-CLIO, LLC.

Miller, C. W. (2013). Sexual Selection: Male-Male Competition'. in J. Losos. (Ed.), The Princeton Guide to Evolution (pp. 267-299). Princeton: Princeton University Press. doi: $10.1515 / 9781400848065-089$

Nettle, D. (2009). Evolution and Genetics for Psychology. Oxford: Oxford University Press.

Paquette, J. A., \& Underwood, M. K. (1999). Gender Differences in Young Adolescents' Experiences of Peer Victimization: Social and Physical Aggression. Merrill-Palmer Quarterly, 45(2), 242-266. doi: 10.1002/pits.20437

Pellegrini, A. D., \& Long, J. D. (2003). A Sexual Selection Theory Longitudinal Analysis of Sexual Segregation and Integration in Early Adolescence. Journal of Experimental Child Psychology, 85(3), 257-278. doi: 10.1016/s0022-0965(03)00060-2

Rosvall, K. A. (2011). Intra-Sexual Competition in Females: Evidence for Sexual Selection? Behavioral Ecology, 22(6), 1131-1140. doi: 10.1093/beheco/arr106 
Salmivalli, C., \& Kaukiainen, A. (2004). “Female Aggression” Revisited: Variable-and PersonCentered Approaches to Studying Gender Differences in Different Types of Aggression. Aggressive Behavior, 30(2), 158-163. doi: 10.1002/ab.20012

Schmitt, D. P., \& Buss, D. M. (1996). Strategic Self-Promotion and Competitor Derogation: Sex and Context Effects on the Perceived Effectiveness of Mate Attraction Tactics. Journal of Personality and Social Psychology, 70(6), 1185-1204. doi: 10.1037//0022-3514.70.6.1185

Schwarz, S., \& Singer, M. (2013). Romantic Red Revisited: Red Enhances Men's Attraction to Young, but not Menopausal Women. Journal of Experimental Social Psychology, 49(1), 161-164. doi: 10.1016/j.jesp.2012.08.004

Shuker, D. M. (2010). Sexual Selection: Endless Forms or Tangled Bank? Animal Behaviour, 79(3), 11-17. doi: 10.1016/j.anbehav.2009.10.031

Singh, D. (1993). Adaptive Significance of Female Physical Attractiveness: Role of Waist-toHip Ratio. Journal of Personality and Social Psychology, 65(2), 293-307. doi: 10.1037/00223514.65.2.293

Smith, M. L., Perrett, D. I., Jones, B. C., Cornwell, R. E., Moore, F. R., Feinberg, D. R., Boothroyd, L. G., Durrani, S. J., Stirrat, M. R., Whiten, S., Pitman, R. M., \& Hillier, S. G. (2006). Facial Appearance is a Cue to Oestrogen Levels in Women. Proceedings of the Royal Society of London B: Biological Sciences, 273(1583), 135-140. doi: 10.1098/rspb.2005.3296

Smith, P. K., Del Barrio, C., \& Tokunaga, R. S. (2013). Definitions of Bullying and Cyberbullying: How Useful Are the Terms. In S. Bauman, D. Cross \& J. Walker. (Ed.), Principles of Cyberbullying Research: Definitions, Measures, and Methodology (pp. 26-40) London: Routledge. 
Smuts, B. B., and Smuts, R. W. (1993). Male Aggression and Sexual Coercion of Females in Nonhuman Primates and Other Mammals: Evidence and Theoretical Implications'. Advances in the Study of Behavior, 22(1763), 1-63. doi: 10.1016/s0065-3454(08)60404-0

Stirrat, M., Gumert, M., \& Perrett, D. (2011). The effect of Attractiveness on Food Sharing Preferences in Human Mating Markets. Evolutionary Psychology, 9(1), 79-91. doi: $10.1177 / 147470491100900110$

Symons, D. (1995). Beauty Is in the Adaptations of the Beholder: The Evolutionary Psychology of Human Female Sexual Attractiveness. In P. Abramson \& S. Pinkerton. (Ed.), Sexual Nature, Sexual Culture (pp. 80-113). Chicago: The University of Chicago Press.

Taylor, P. A., \& Glenn, N. D. (1976). The utility of education and attractiveness for females' status attainment through marriage. American Sociological Review, 41, 484-498. doi: $10.2307 / 2094255$

Tooby, J. and Cosmides, L. (2005). Conceptual Foundations of Evolutionary Psychology. In D. Buss. (Ed.), The Handbook of Evolutionary Psychology (pp. 5- 63). New Jersey: John Wiley \& Sons Inc. doi: 10.1002/9780470939376.ch1

Trivers, R. L. (1972). Parental investment and sexual selection. In B. Campbell (Ed.), Sexual selection and the descent of man, 1871-1971 (pp. 136-179). Chicago, IL: Aldine.

Udry, J. R., \& Eckland, B. K. (1984). Benefits of being attractive: Differential payoffs for men and women. Psychological Review, 54, 47-56. doi: 10.2466/pr0.1984.54.1.47

Underwood, M. K., Beron, K. J., \& Rosen, L. H. (2009). Continuity and Change in Social and Physical Aggression from Middle Childhood through Early Adolescence. Aggressive Behavior, 35(5), 357-375. doi: 10.1002/ab.20313 
Vaillancourt, T. (2013). Do Human Females Use Indirect Aggression as an Intra-Sexual Competition Strategy?'. Philosophical Transactions of the Royal Society B: Biological Sciences, 368, 1631. doi: 10.1098/rstb.2013.0080

Vaillancourt, T., \& Sharma, A. (2011). Intolerance of sexy peers: Intrasexual competition among women. Aggressive Behaviour, 37(6), 569-577. doi: 10.1002/ab.20413

Vaillancourt, T., Miller, J. L., \& Sharma, A. (2010).'Tripping the Prom Queen’: Female IntraSexual Competition and Indirect Aggression. in K. Österman. (Ed.), Indirect and Direct Aggression (pp. 17-32) Germany: Peter Lang.

Waynforth, D. (2001). Mate Choice Trade-Offs and Women's Preference for Physically Attractive Men. Human Nature, 12(3), 207-219. doi: 10.1007/s12110-001-1007-9

Webb, L. M. (2015). Shame Transfigured: Slut-Shaming from Rome to Cyberspace. First Monday, 20(4), Available online at www.journals.uic.edu/ojs/index.php/fm/article/view/5464. doi: 10.5210/fm.v20i4.5464

White, D. D., Gallup, A. C., \& Gallup, G. G. (2010). Indirect Peer Aggression in Adolescence and Reproductive Behavior. Evolutionary Psychology, 8(1), 49-65. doi: $10.1177 / 147470491000800106$

Workman, L., \& Reader, W. (2014). Evolutionary Psychology. Cambridge: Cambridge University Press. doi: 10.1017/cbo9781139164757 
Table 1. Descriptive statistics relating to intra-sexual competition scores and derogatory words for each condition.

\begin{tabular}{lllll}
\hline DV & Condition & Mean & Standard & Standard \\
& & & Deviation & Error \\
\hline Intra-sexual competition score & Conservative & 25.20 & 9.75 & 1.78 \\
& Provocative & 33.26 & 13.51 & 2.28 \\
No. of derogatory words & Conservative & 1.10 & .37 & .07 \\
& Provocative & 1.31 & .53 & .09 \\
No. of complimentary words & Conservative & 5.03 & 2.08 & .38 \\
& Provocative & 3.50 & 1.60 & .27 \\
\hline
\end{tabular}

